\title{
Giant kelp (Macrocystis) fishery in Atacama (Northern Chile): biological basis for management of the integrifolia morph
}

\author{
Renato Westermeier • Pedro Murúa • David J. Patiño • \\ Liliana Muñoz • Dieter G. Müller
}

\begin{abstract}
In Bahia Chasco, Atacama, the integrifolia morph of Macrocystis forms one of the most important kelp forests in northern Chile. In order to determine effects of local harvesting policies, we evaluated the population dynamics of this resource in intact, frequently disturbed, and permanently and completely harvested areas. Recruitment, frond length, reproductive phenology and standing crop were assessed monthly. In intact areas, frond length and ratio of reproductive individuals were higher, but recruitment was poorly stimulated. On the other hand, complete harvest had an important effect on Macrocystis population dynamics. Whereas recruitment and growth were much higher after harvest events, reproductive phenology was lower. The harvest techniques with different frequencies practiced by Bahia Chasco fishermen were less harmful than complete harvest, and we conclude that current exploitation techniques applied in this location are not deleterious for the giant kelp beds. They even have favorable effects by renewing the population through stimulation of sexual reproduction, recruitment and growth of young individuals.
\end{abstract}

Keywords Macrocystis · integrifolia morph · Population dynamics · Intact areas · Disturbed areas · Recruitment · Frond length $\cdot$ Reproductive phenology $\cdot$ Harvesting $\cdot$ Bahia Chasco

R. Westermeier $(\bowtie) \cdot$ P. Murúa $\cdot$ D. J. Patiño $\cdot$ L. Muñoz

Instituto de Acuicultura, Universidad Austral de Chile, Sede Puerto Montt, Casilla, 1327 Puerto Montt, Chile

e mail: rwesterm@uach.cl

D. G. Müller

Fachbereich Biologie der Universität Konstanz, 78457 Konstanz, Germany

\section{Introduction}

Harvesting of giant kelp has been continuously increasing over the past nine decades (North 1994). Especially on the US Pacific coast, it stimulated research dealing with the problem of overharvesting. Various studies showed that harvesting of Macrocystis canopies does not have significant effects on forest survival (Kimura and Foster 1984; Druehl and Breen 1986). Furthermore, they helped to improve the regulations and management protocols of this resource. Currently, kelp management in North America allows cutting no deeper than $1-2 \mathrm{~m}$ beneath the surface. Based on many years of practice, a system of exploitation licenses, royalties and harvest plans resulted (California Department of Fish and Game 2004), which stabilizes kelp harvesting activity (Graham et al. 2007).

The situation in Chile is quite different. Traditionally, two species of Macrocystis are distinguished, Macrocystis pyrifera in the South and Macrocystis integrifolia from $32^{\circ} \mathrm{S}$ northward. Since molecular and biological data suggest conspecificity of these two taxa (Westermeier et al. 2007; Demes et al. 2009; Macaya and Zucarello 2010), we use the term "morph" to distinguish between them. Populations of the pyrifera morph in South Chile have not been subject to significant extractive pressure. In contrast, the northern kelp beds of the integrifolia morph have been strongly harvested for more than 3 decades under poor and inappropriate regulations. Extraction of the kelp canopy by collecting the floating portion to $1.5 \mathrm{~m}$ below the surface, followed by pruning of all biomass above the holdfast, was established as a standard harvesting protocol by the Chile Subsecretary of Fisheries (SUBPESCA). Since this procedure did not satisfactorily work for the integrifolia morph, individual fishermen in Bahia Chasco have developed their own harvesting and management systems. 
Bahia Chasco, Atacama, supports one of the most important Macrocystis populations in northern Chile (Westermeier et al. 2013a). With an area of $280-380$ ha (Zavala et al. 2010), this kelp forest offers habitat, substratum, food and wave protection for a highly diverse marine ecosystem of fishes, invertebrates and understory marine algae (Westermeier et al. 2012 unpublished). Important fishery stock like Concholepas concholepas (Mollusca) and Genypterus ssp. (Pisces) are harvested from this kelp bed. Despite this species richness, Macrocystis is the most valuable resource of Bahia Chasco. Up to $40 \mathrm{t}$ of fresh weight are harvested daily as food supply for abalone mariculture, which illustrates its broad social and economic function for local fishermen (Westermeier et al. 2012). Kelp extraction is practically continuous throughout the year. Due to its legal status as "free access area", increasing numbers of foreign fishermen enter the area. This fact called for experimental research on kelp repopulation (Westermeier et al. 2013a, b, c) as a precautionary strategy in anticipation of overharvesting problems. Despite the unquestioned impact of harvesting activities, the Bahia Chasco kelp population seems to maintain its biomass with some degree of seasonal variability. Intrinsic variables of the habitat seem to affect biomass fluctuations more than the controlled activity of local fishermen. This conclusion is in contradiction with several previous studies, which reported Macrocystis overexploitation in Bahia Chasco and other localities in northern Chile (Graham et al. 2007; BorrasChavez et al. 2012). In order to clear this discrepancy, we studied and compared the population biology of disturbed (harvested) and non-disturbed (intact) areas within the Bahia Chasco kelp forest.

\section{Materials and methods}

Our study was carried out between May 2011 and May 2013, in Bahia Chasco, Atacama ( $27^{\circ} 41^{\prime} \mathrm{S} ; 71^{\circ} 00^{\prime} \mathrm{W}$; Fig. 1). In this location, water temperature and light penetration have opposite seasonal trends. While temperature oscillated between $13{ }^{\circ} \mathrm{C}$ and $19{ }^{\circ} \mathrm{C}$, water transparency by Secchi disk measurements ranged between 3 and $25 \mathrm{~m}$, with the maximum in winter. Nutrients also vary seasonally. Maximum concentrations of nitrate and orthophosphate have been recorded in winter months (212 and $84 \mu \mathrm{g} \mathrm{L}{ }^{1}$, respectively). Ammonium values were much lower $\left(<10 \mu \mathrm{g} \mathrm{L}{ }^{1}\right)$. Sea bottom formations are dominated by metamorphic rock, which we selected for our study areas, apart from some sand/shell patches with boulders.

\section{Population biology}

Our population studies were carried out in three sections:

a) Intact areas: we marked a $20-\mathrm{m}^{2}$ area within the Bahia Chasco kelp bed, which remained untouched. With a monthly frequency, we quantified from twenty $1 \mathrm{~m}^{2}$ quadrats $(n=20)$ cumulative recruitment, average thallus length and reproductive phenology. The cumulative recruitment (recruits $\mathrm{m}^{2}$ ) was measured by identifying and counting new and older recruits, in each $1 \mathrm{~m}^{2}$ replicate. Average frond length $(\mathrm{cm})$ was determined by measuring all thalli in each $1 \mathrm{~m}^{2}$ replicate. Reproductive phenology was expressed as the percentage of reproductive individuals.

b) Completely disturbed (harvested) areas: In areas of $20 \mathrm{~m}^{2}$, we harvested fresh Macrocystis biomass once per season (four harvests in total: May, July and November 2011 and January 2012), removing all visible individuals of kelp and other prominent algae (i.e. Ulva taeniata, Asparagopsis armata), including their holdfast. Only crustose algae (i.e. Mesophyllum sp) remained on the substrata. Re-appearing Macrocystis individuals were quantified monthly in each of twenty $1 \mathrm{~m}^{2}$ quadrats.
Fig. 1 Study area, Bahia Chasco, Atacama region, Chile. After Westermeier et al. (2013c)

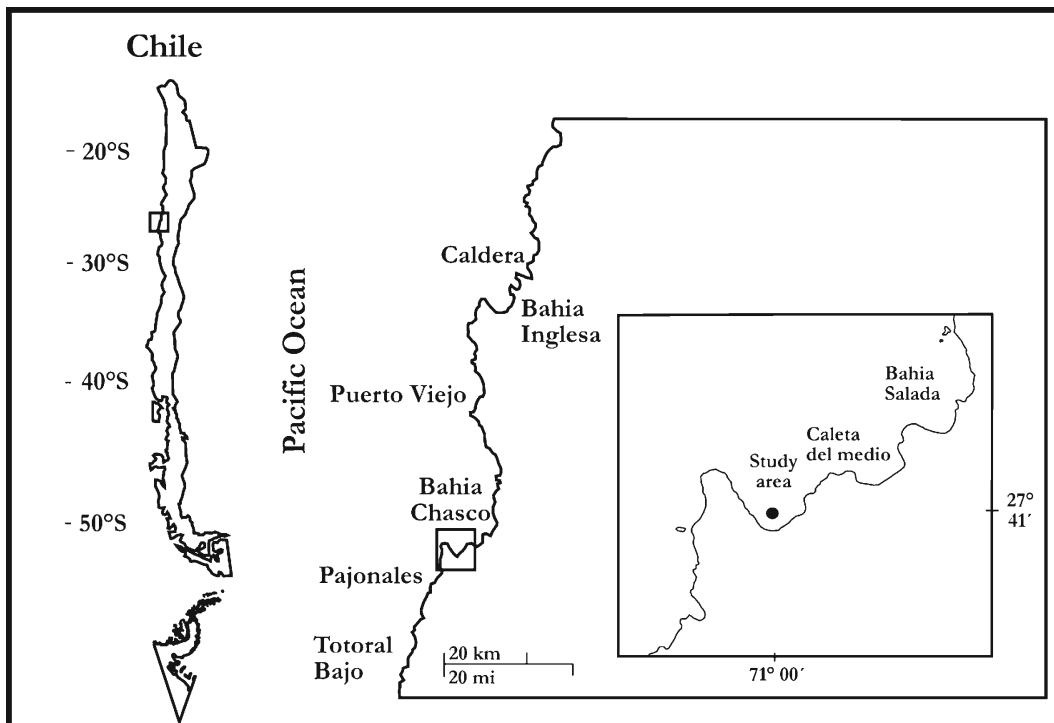



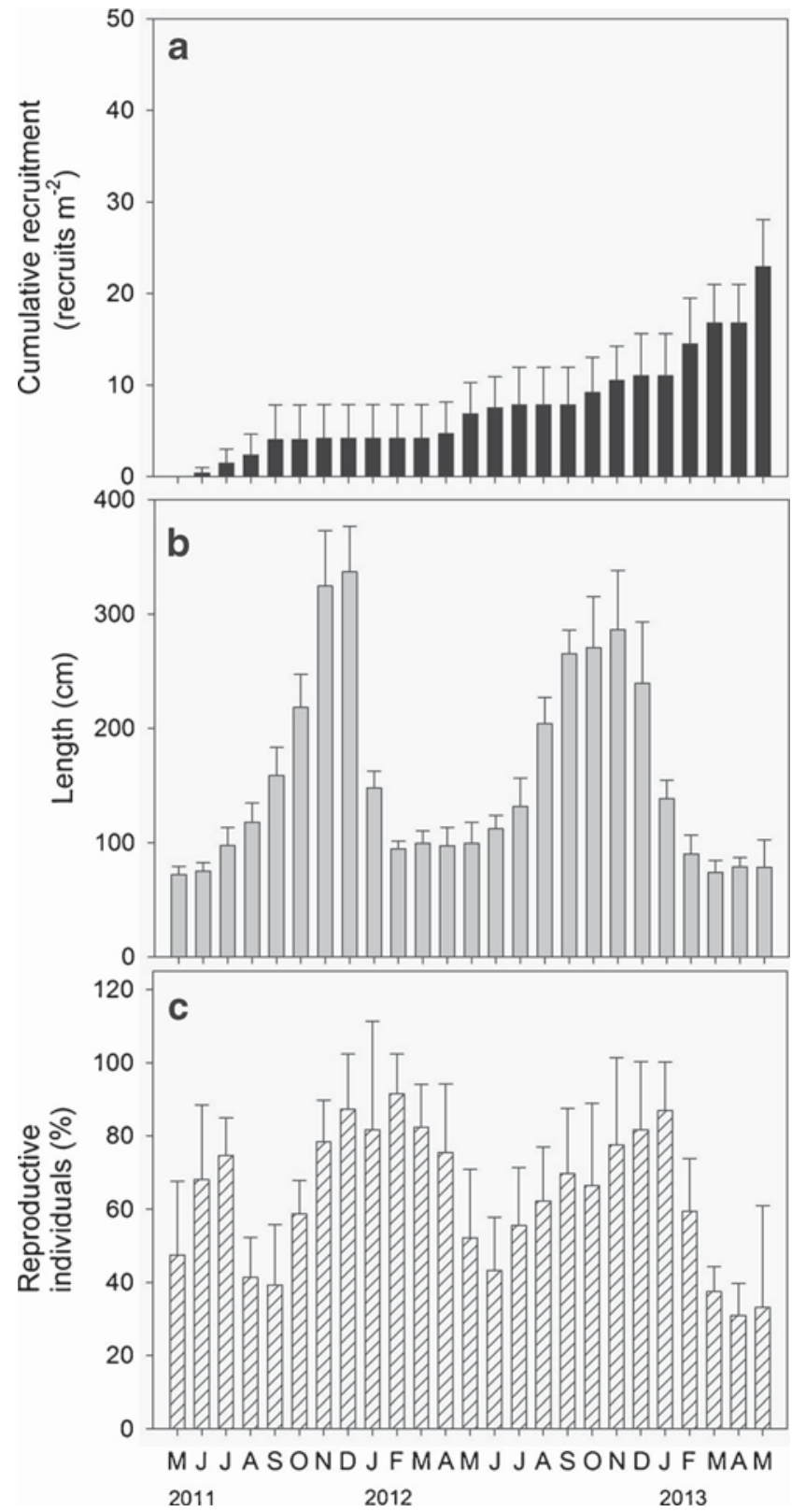

Fig. 2 Population biology of Macrocystis in an intact area of Bahia Chasco. a Cumulative recruitment, $\mathbf{b}$ average frond length and $\mathbf{c}$ repro ductive phenology c) Frequently disturbed (harvested) areas: Within the Bahia Chasco kelp bed, six areas of $20 \mathrm{~m}^{2}$ were selected and marked in June 2011. Each one was subject to a different harvesting frequency: monthly, bimonthly and quarterly regimes. Harvesting protocol followed local fishermen's procedures: non-directed total removal of old and weak fronds and "pruning" of young individuals. Under this method, parts of holdfasts, some stipes and fronds were allowed to remain usually. Population variables were measured before harvesting.

\section{Statistical analysis}

Statistical comparisons of population parameters in intact and disturbed zones were conducted through Sigmaplot 11.0 (Systat Software, Inc.). Cumulative recruitment, frond length, reproductive phenology and standing crop were compared by non-parametric Kruskal Wallis test, since a posteriori tests were not successful (Zar 1999). Percentage values of reproductive phenology were angularly transformed after Zar (1999) recommendations. Comparison between intact and disturbed areas was made by taking data in four seasons of the year in order to compare the different treatments in the same temporal scales. Harvest occurrences comparisons were carried out comparing each harvest regimes. In the case of standing crop, comparisons were made selecting the month of the highest yield in each harvest frequency.

\section{Results}

Intact area

Population dynamic indexes in the non-disturbed area are shown in Fig. 2. Cumulative recruitment was low (23 recruits $\mathrm{m}^{2}$ in two years; Fig. 2a). Average frond length of Macrocystis showed a clear seasonal periodicity (Fig. 2b). The largest thalli were always found in spring, with individuals up to $3-5 \mathrm{~m}$ (Fig. 2b, Table 1). After summer, frond length sharply decreased to $70-90 \mathrm{~cm}$ in autumn and winter.
Table 1 Statistical results of seasonality and harvest frequency on population parameters

Intact area: productivity seasonal variation. Completely harvested area: seasonal interventions com parison. Frequently harvested ar ea: Harvest frequency comparison $*_{p}<0.05, * *_{p} \geq 0.05$

\begin{tabular}{|c|c|c|c|c|c|c|c|c|}
\hline \multirow[t]{2}{*}{ Treatment } & \multicolumn{2}{|c|}{ Recruitment } & \multicolumn{2}{|l|}{ Length } & \multicolumn{2}{|c|}{ Reproductive phenology } & \multicolumn{2}{|c|}{ Standing crop } \\
\hline & $H$ value & $p$ & $H$ value & $p$ & $H$ value & $p$ & $H$ value & $p$ \\
\hline \multicolumn{9}{|l|}{ Intact area } \\
\hline Seasonal variation & 47.000 & $*$ & 40.936 & $*$ & 33.788 & $*$ & & \\
\hline \multicolumn{9}{|c|}{ Completely harvested area } \\
\hline Seasonal variation & 18.441 & $*$ & 14.420 & * & 16.255 & $*$ & & \\
\hline \multicolumn{9}{|c|}{ Frequently harvested area } \\
\hline Harvest frequency & 5.456 & $* *$ & 15.158 & * & 4.082 & $* *$ & 4.012 & $* *$ \\
\hline
\end{tabular}


Fig. 3 Cumulative recruitment of Macrocystis, under complete seasonal harvests. a Autumn, b winter, c spring, and $\mathbf{d}$ summer

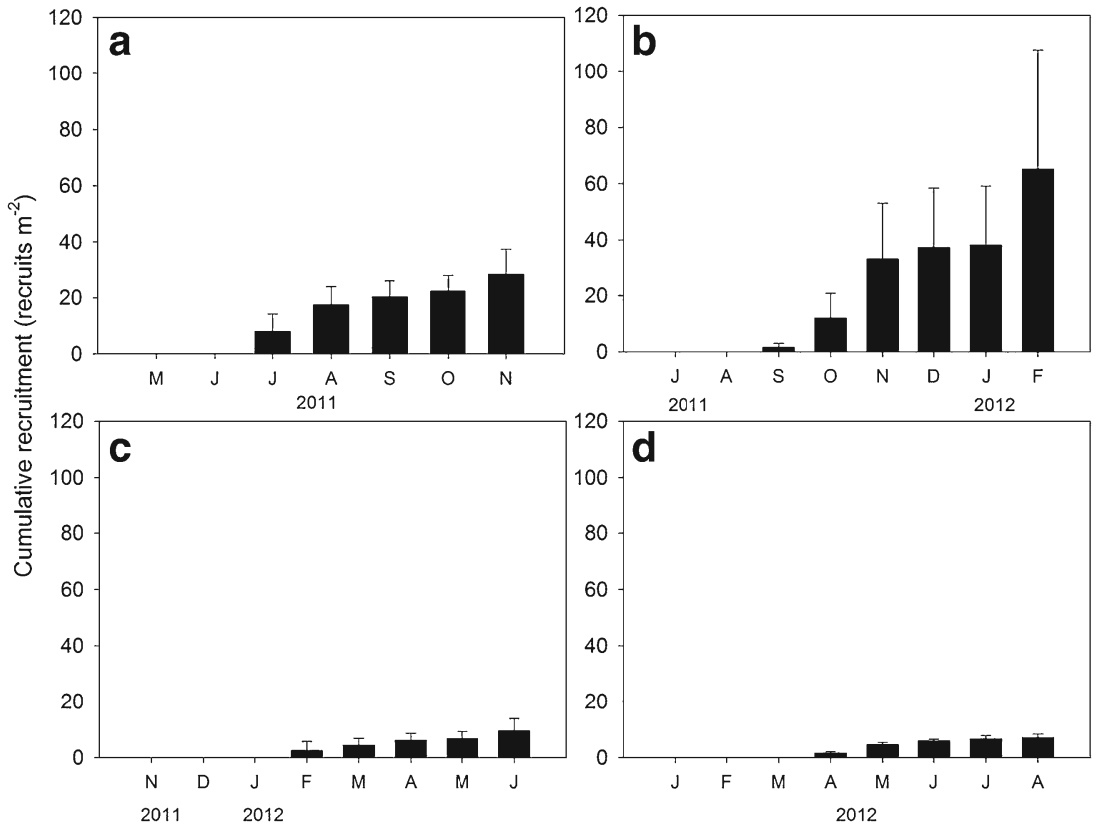

Toward next spring, growth accelerated, starting a new cycle. This perennial population was permanently fertile, with seasonal variation (Fig. 2c), showing maximum values in summer, and lower values in winter $(p<0.05$; Table 1$)$, although an exceptionally high reproductive index was detected in winter 2011

\section{Completely disturbed areas}

Figures 3, 4, and 5 show population indexes after total harvests at different seasons. First Macrocystis individuals were visible $2-3$ months after intervention, and recruitment was stimulated by the harvests, up to 20 times in comparison with intact areas (Fig. 3). Maximum values of cumulative recruitment were detected under autumn and winter harvests (30 and 65 recruits $\mathrm{m}^{2}$, respectively; Figs. 3a, b; Table 1). Spring and summer harvests resulted in lower recruitments $(\approx 7-$ 10 recruits $\mathrm{m}^{2}$ in 7 months; Figs. $3 \mathrm{c}, \mathrm{d}$ ).

Growth of Macrocystis recruits: The total harvest areas exhibited similar seasonal tendencies within a shorter temporal scale (Fig. 4). Best growth was recorded under spring and summer harvest regimes, with values of $\approx 130 \mathrm{~cm}$ in 4 months $(p<0.05$; Table 1; Fig. 4c, d). In contrast, thalli in winter harvest areas showed irregular growth, and sporophytes did
Fig. 4 Growth of Macrocystis under complete seasonal harvests. a Autumn, $\mathbf{b}$ winter, $\mathbf{c}$ spring and d summer
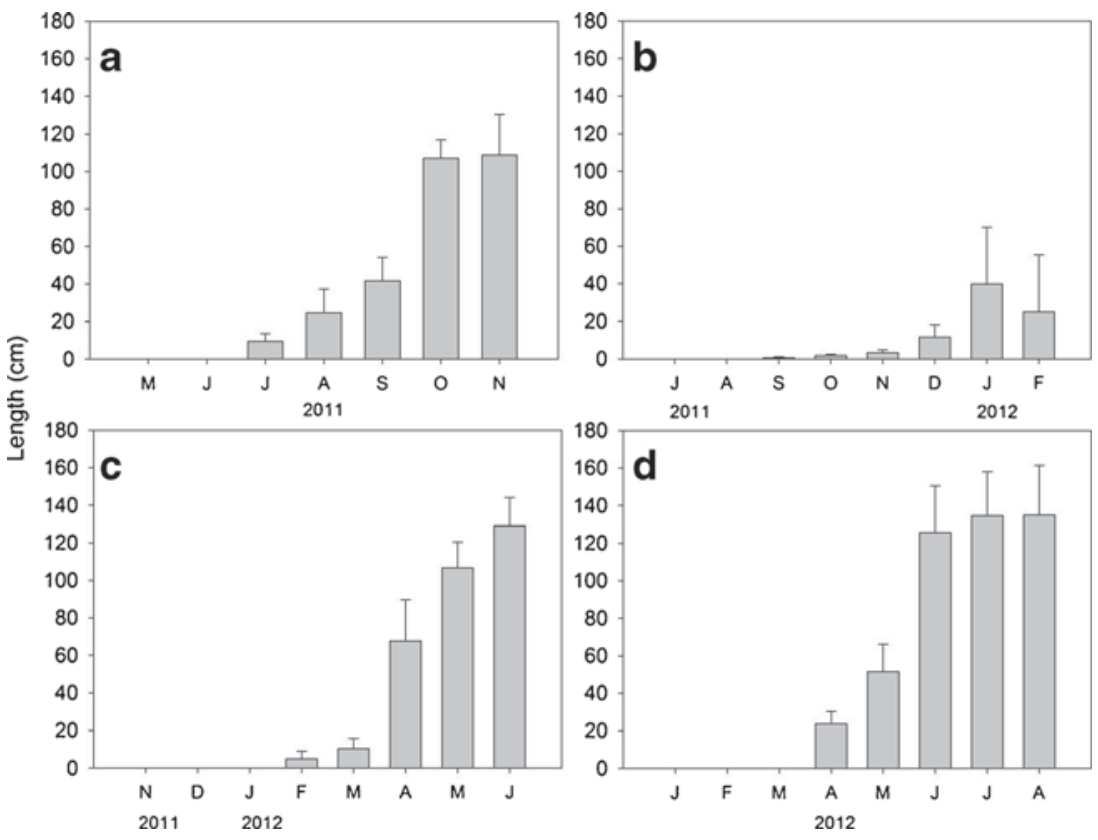
Fig. 5 Reproductive phenology of Macrocystis under complete seasonal harvests. a Autumn, b winter, $\mathbf{c}$ spring and d summer
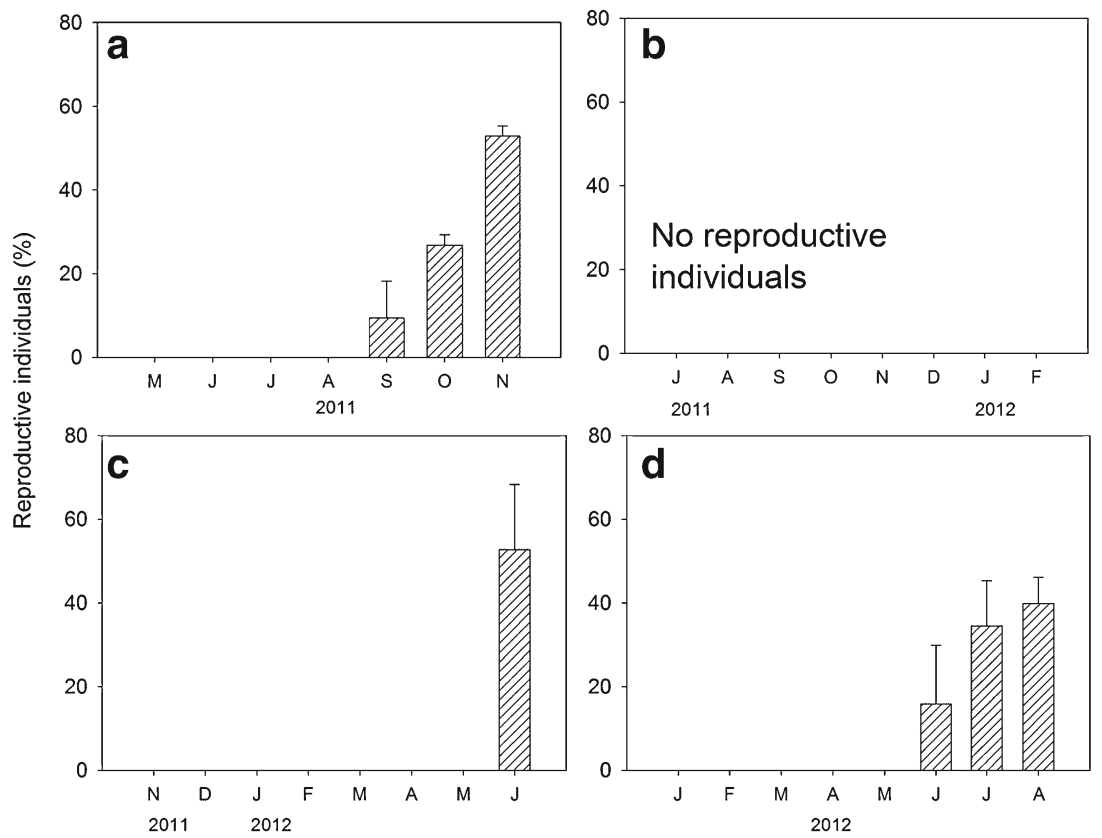

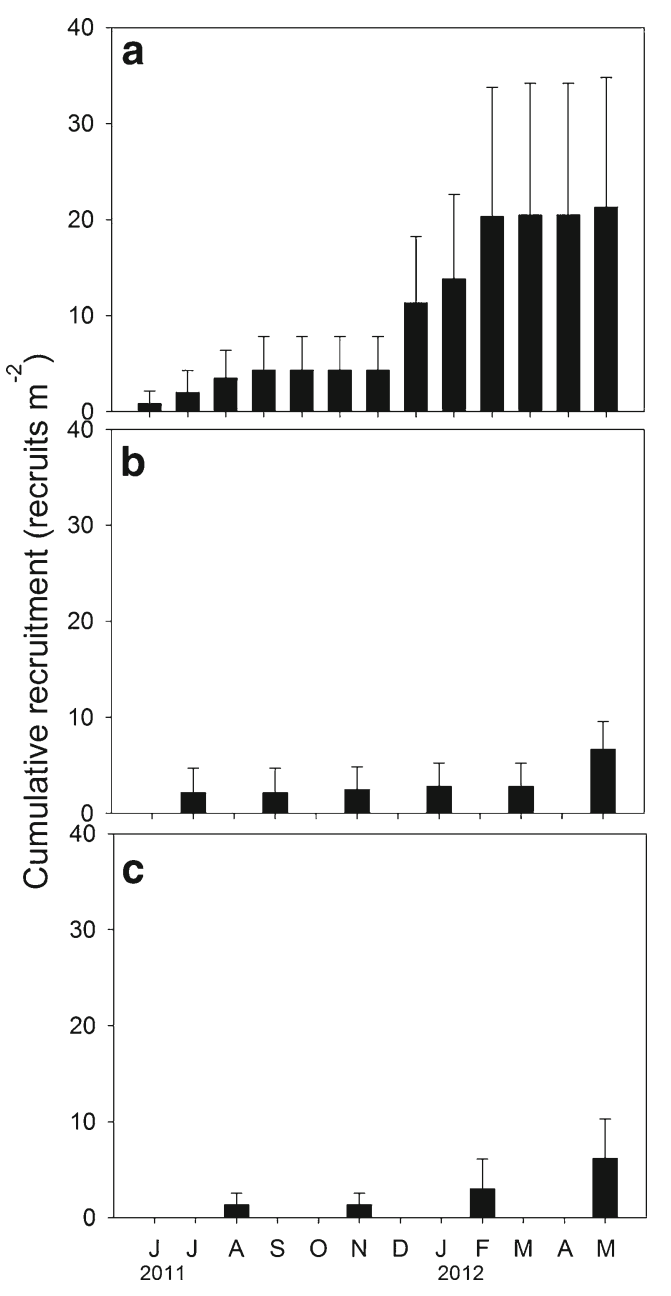

Fig. 6 Cumulative recruitment of Macrocystis under different harvest frequencies. a Monthly, b bimonthly and $\mathbf{c}$ quarterly

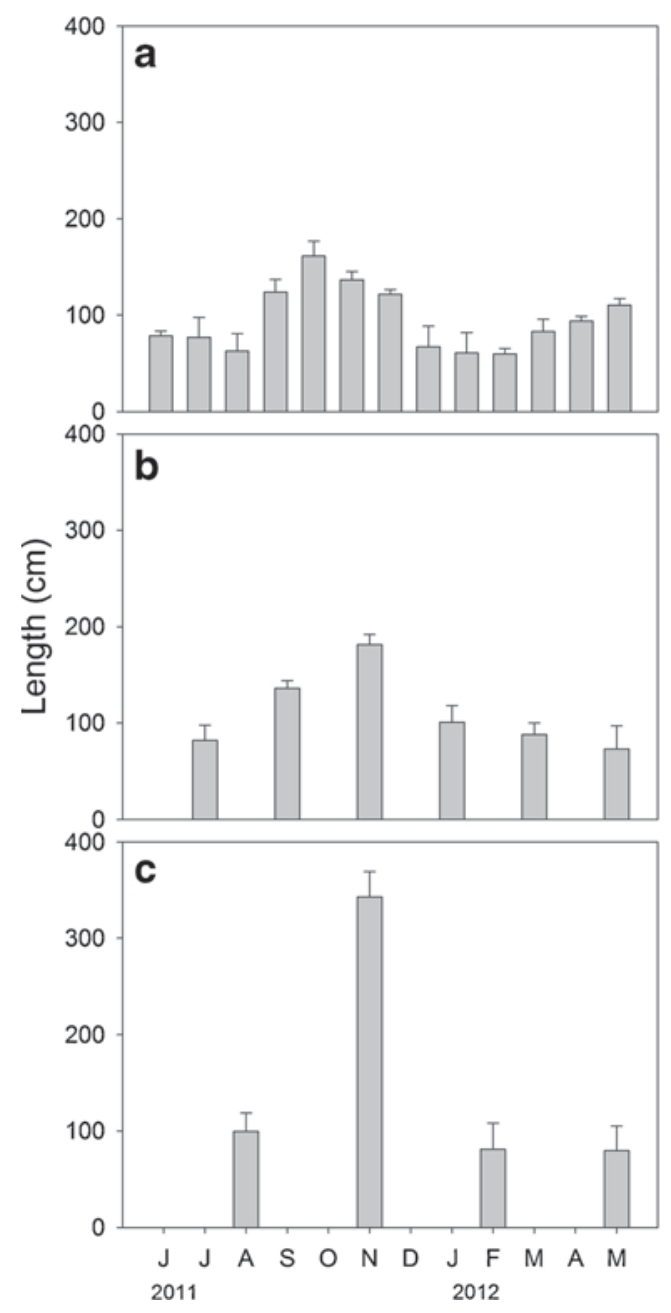

Fig. 7 Growth of Macrocystis under different harvest frequencies. a Monthly, b bimonthly and $\mathbf{c}$ quarterly 

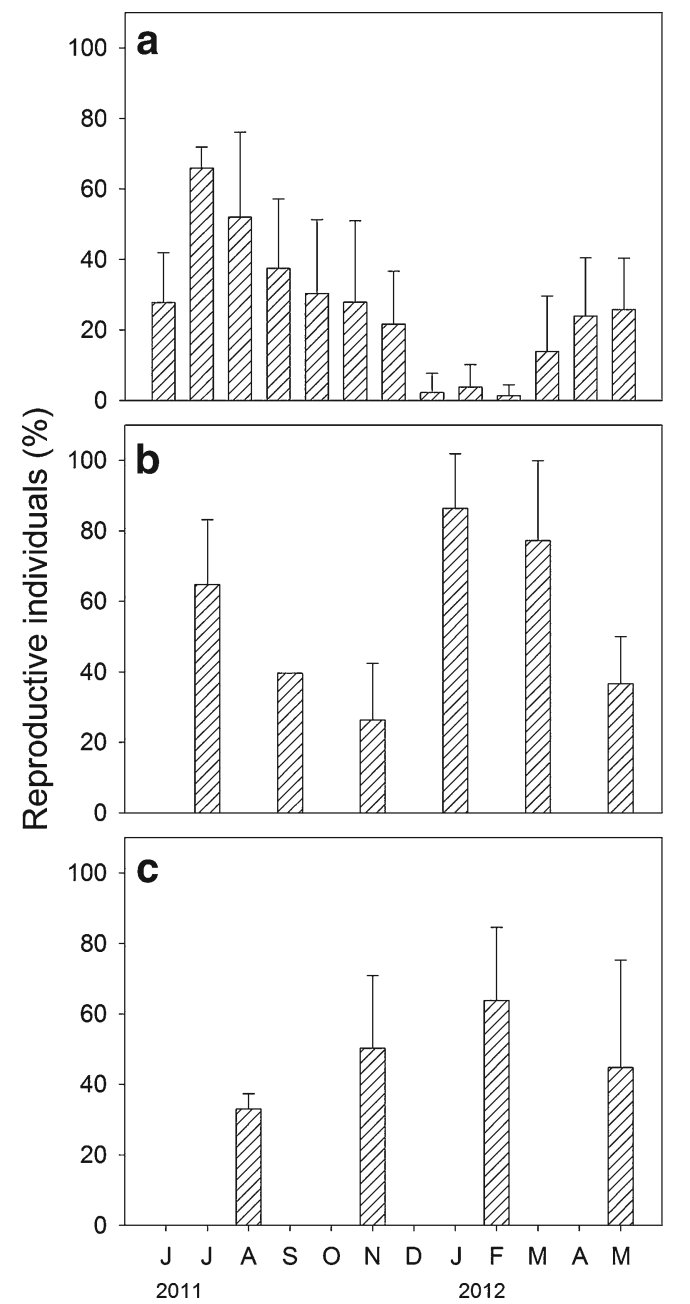

Fig. 8 Reproductive phenology of Macrocystis under different harvest frequencies. a Monthly, b bimonthly and $\mathbf{c}$ quarterly

not exceed $40 \mathrm{~cm}$ in average in 7 months (Fig. 4b). Within 8 months, up to $50 \%$ of individuals became reproductive in disturbed areas (Figs. 5a, c, d), except for winter harvest areas, where individuals did not reach maturity (Fig. 5b).

Frequently disturbed (harvested) areas

Figures 6, 7, 8, and 9 illustrate population variability under different harvest frequencies. Recruitment in areas under bimonthly and quarterly regimes was the lowest $(<10$ recruits $\mathrm{m}^{2}$ throughout one year; Figs. $6 \mathrm{~b}, \mathrm{c}$ ) and similar to intact areas. With monthly frequency, instead, recruitment was higher (Fig. 6a), but there was a not significant difference among treatments since values dispersion of the replicates were high as well (Table 1).

While under monthly harvesting frequency Macrocystis thalli did not reach $180 \mathrm{~cm}$ (Fig. 7a), under bimonthly and quarterly harvesting regimes they exceeded 200 and $320 \mathrm{~cm}$, respectively $(p<0.05$; Table 1 ; Figs. $7 \mathrm{~b}, \mathrm{c})$. Under all harvesting regimes, highest values were recorded in spring.
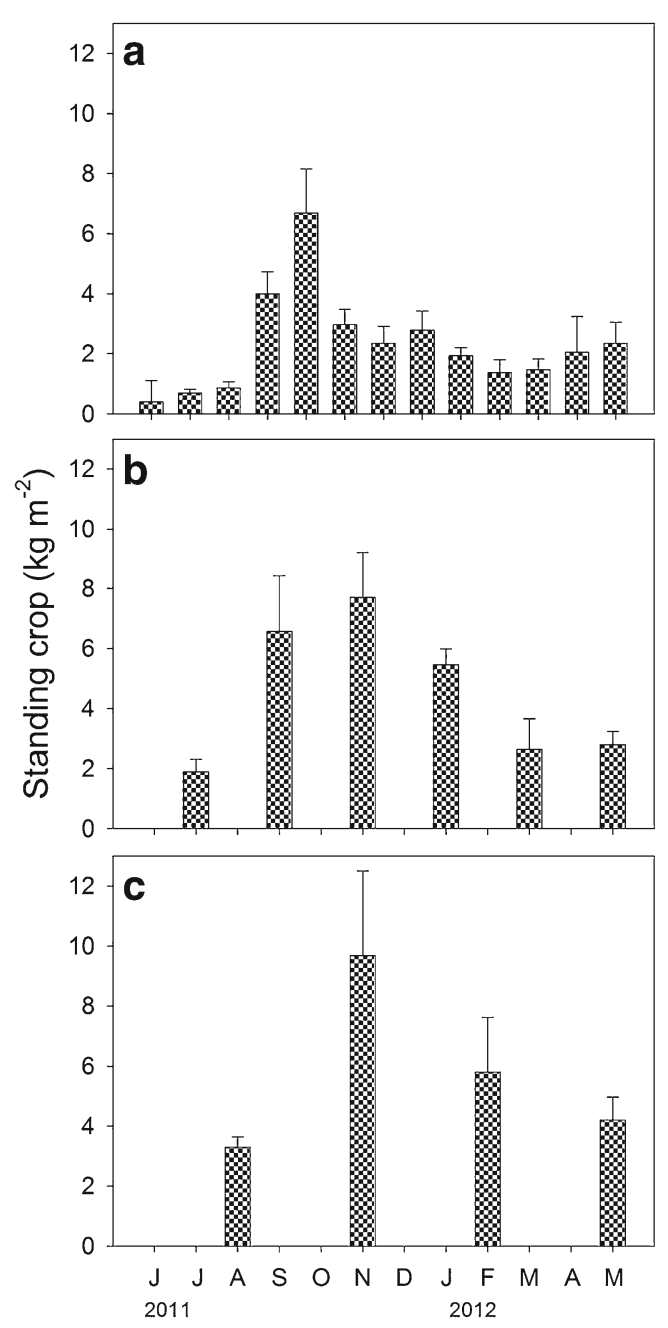

Fig. 9 Standing crop of Macrocystis under different harvest frequencies. a Monthly, b bimonthly and $\mathbf{c}$ quarterly

Reproductive phenology showed different non-significant tendencies (Fig. 8; Table 1). In the area with monthly harvest frequency, the proportion of reproductive individuals decreased dramatically toward late summer $(<5 \%$; Fig. 8a). In areas with bimonthly frequencies of harvest this minimum occurred two months earlier, and values were much higher (25-80\%; Fig. 8b). Under quarterly harvesting regime, reproductive phenology trend was opposite, with lowest values in winter (Fig. 8c). The proportion of reproductive individuals, however, was similar among all harvest treatments (Table 1).

The yield (standing crop) of each harvest regime, in terms of fresh biomass, is shown in Fig. 9. Harvesting with monthly frequency resulted in low but frequent recurrent productivity, especially in winter months (fresh biomass $<1 \mathrm{~kg} \mathrm{~m}^{2}$ per month, Fig. 9a). This level of productivity increased strongly to over sixfold in spring. Similar seasonality was observed in the bimonthly and quarterly treatments. Productivity per harvest was higher, and biomass surpassed $8 \mathrm{~kg} \mathrm{~m}^{2}$ and $12 \mathrm{~kg} \mathrm{~m}^{2}$, respectively. In summary, total productivity per year (total and 
maximum values) was similar under all regimes, and no statistically significant differences could be detected (Table 1).

\section{Discussion}

Patterns of recruitment, growth and fertility in kelps have shown a clear dependence on intra-population competition (Lobban and Harrison 1994). This applies also to Macrocystis in Chile, and is described in numerous population studies (Santelices and Ojeda 1984a; b; Westermeier and Möller 1990; Vega et al. 2005; Buschmann et al. 2006). In our study, greater frond length in the intact area (i.e. in spring) was correlated with poorer recruitment, presumably due to several limiting variables: substrata, light penetration and nutrient availability. In periods, when the fronds were smallest $(\approx 70 \mathrm{~cm})$ in this area, they were too abundant to initiate sexual reproduction in the understory kelp gametophytes. Therefore, recruitment was discontinuous and connected to "windows" with optimal conditions, similar to Macrocystis populations from other latitudes (Reed and Foster 1984; Druehl and Wheeler 1986; Westermeier and Möller 1990).

The survival of old plants can be explained by vegetative propagation. The integrifolia morph has a stonoliferous holdfast (Westermeier et al. 2012, 2013a). New individuals spread and colonize nearby substrata starting from the holdfast (Westermeier et al. 2013b). This strategy has been rarely mentioned in the literature (Druehl and Kemp 1982; Graham 1996; Westermeier et al. 2013a), but it is probably the most important factor responsible for fast recovery in integrifolia populations, especially in northern Chile. Thus, apart from adverse extrinsic factors, adult integrifolia sporophytes will be apt to live as long as they remain attached to their substratum, which means two years or even much longer. Until now, the lifespan of this potentially long-lived kelp has not yet been exactly determined (Graham et al. 2007).

Before our harvesting experiments started, the integrifolia individuals presumably showed similar dynamics as in the intact areas. Our harvesting activities undoubtedly encouraged recruitment within the population, because it reduced the forest density and frond length within the canopy (Santelices and Ojeda 1984a; Graham et al. 1997). Consequently, sexual reproduction is stimulated, and density subsequently increases by massive recruitment.

In our study, total harvesting activities in autumn and winter were the highest, but only autumn recruits produced adult individuals. Actually, winter recruits seemed to die off after few weeks, providing space for new recruitment. Alternatively, young individuals may remain in a state of latency as reported by Santelices and Ojeda (1984a) and Graham et al. (1997). Such individuals then grow rapidly to adult size when densities decrease and conditions become favorable. Spring and summer harvests generated low levels of recruitment, but under these regimes our kelp populations recovered to their initial status faster. It can be assumed that recruitments were low only because substratum was rapidly covered by high-performance sporophytes. Consequently, spring and summer should be the best season for harvesting activities.

Reproductive phenology is an important factor in giant kelp population biology. As reported in several studies by Reed et al. (1996), Vega et al. (2005), Vásquez et al. (2006)) and Graham et al. (2007), reproductive individuals of Macrocystis can be found throughout the year in subtidal populations. In Bahia Chasco, giant kelp recruits took 4 7 months to become reproductive. Furthermore, high reproductive values were often followed by a decrease in the average frond length, which indicates a deterioration of thallus tissue after spore release (Westermeier and Möller 1990; Graham et al. 2007). Since the vitality of meiospores varies seasonally in several kelp species (Lee and Brinkhuis 1988; Vega et al. 2005; Murúa et al. 2013), further studies are required to assess the quantity and quality of sorus tissue and spores, and their seasonal variability in the field.

Our findings on Macrocystis population biology may not only reflect intrinsic population factors, but also environmental variables. Seawater temperature in Bahia Chasco does not show abrupt changes, thus it is likely that it moderates the rate of biological processes rather than triggering them (Lobban and Harrison 1994). In contrast, water transparency decreased dramatically in summer, presumably due to microalgal blooms (Murúa et al. 2013). As a consequence, our Bahia Chasco Macrocystis population exhibited a sharp decrease in terms of recruitment, frond length, substrate cover and biomass. This is in accordance with the conclusion by Graham et al. (2007), that light is one of the most important factors in Macrocystis canopy productivity. Furthermore, nutrients such as nitrates and phosphates are available in higher concentrations in winter, being available for algae in spring. In summary, several environmental factors cooperate to create optimum conditions for kelp reproduction and growth in the spring season.

Our harvest frequency experiments, based on Bahia Chasco fishermen's techniques, confirm that the current harvesting methods in this location offer several advantages.

a) Recruitment results were intermediate between intact and completely disturbed areas. Major values were obtained, nevertheless, with monthly frequencies of harvest.

b) Growth is steady, and even stimulated - especially in spring - under all harvest regimes, regardless of their frequency.

c) At any given time approx. 50\% of individuals are reproductive, which ensures a constant supply of spores.

d) Standing crop was high under all harvest treatments, except for monthly harvests in winter months. Highest biomass is obtained in spring. 
The results of our study not only demonstrate the relationship between harvest regimes and population dynamics. They also offer the chance to design a management plan for the Bahia Chasco kelp bed, based on different harvest frequencies and area rotation.

Furthermore, our study confirmed the effectiveness of the present harvest techniques by Bahia Chasco fishermen, who practice instinctively the thinning of weak adult specimens and the pruning of younger individuals. This method is strongly superior to direct pruning as suggested by Borras-Chavez et al. (2012) or complete harvest recommended by some Chilean government organizations (Graham et al. 2007), which often are poorly profitable or take a long time.

Based on these considerations, we conclude that present fishermen's activities in Bahia Chasco are not deleterious for the local kelp bed. In contrary, their activities provide a good standing crop, and also promote sexual reproduction, recruitment and growth of young individuals. Without this interference, significant loss could occur by the normal population dynamics of integrifolia morph, without commercial utilization or social benefit. However, it will be highly urgent, to control the number of local fishermen working in this free access area. Excessively high harvest pressure will lead to major over-exploitation levels, followed by ecological disorders in Bahia Chasco and other integrifolia kelp beds in northern Chile.

Acknowledgments The funding of this study was granted to RW by Gobierno Regional de Atacama (Fondo a la Innovación y la Competividad FIC), through 2010 and 2011 grants. We thank for com ments by two anonymous reviewers. The technical support by Carlos Atero (Laboratorio de Macroalgas UACh) and Claudio Soza (Bahia Chasco fisherman) is also acknowledged.

\section{References}

Borras Chavez R, Edwards M, Vásquez JA (2012) Testing sustainable management in Northern Chile: harvesting Macrocystis pyrifera (Phaeophyceae, Laminariales). a case study. J Appl Phycol 24:1655 1665

Buschmann AH, Moreno CA, Vásquez JA, Hernández González MC (2006) Population and reproduction strategies of Macrocystis pyrifera (Phaeophyta) in southern Chile. J Appl Phycol 18:575 582

California Department of Fish and Game (2004) Annual status of the fisheries report through 2003. 182 p. Available at: www.portal. nceas.ucsb.edu

Demes KW, Graham MH, Suskiewicz TS (2009) Phenotypic plasticity reconciles incongruous molecular and morphological taxonomies: the giant kelp, Macrocystis (Laminariales, Phaeophyceae), is a monospecific genus. J Phycol 45:1266 1269

Druehl LD, Kemp L (1982) Morphological and growth responses of geographically isolated Macrocystis integrifolia populations when grown in a common environment. Can J Bot 60:1409 1413

Druehl LD, Breen PA (1986) Some ecological effects of harvesting Macrocystis integrifolia. Bot Mar 29:97 103
Druehl LD, Wheeler WN (1986) Population biology of Macrocystis integrifolia from British Columbia, Canada. Mar Biol 90:173 179

Graham MH (1996) Effect of high irradiance on recruitment of giant kelp Macrocystis (Phaeophyta) in shallow water. J Phycol 32:903 906

Graham MH, Harrold C, Lisin S, Light K, Watanabe JM, Foster MS (1997) Population dynamics of giant kelp Macrocystis pyrifera along a wave exposure gradient. Mar Ecol Prog Ser 148:269 279

Graham MH, Vásquez JA, Buschmann AH (2007) Global ecology of the giant kelp Macrocystis: from ecotypes to ecosystems. Oceanogr Mar Biol 45:39 88

Kimura RS, Foster MS (1984) The effects of harvesting Macrocystis pyrifera on the algal assemblage in a giant kelp forest. Hydrobiologia 116/117:425 428

Lee JA, Brinkhuis BH (1988) Seasonal light and temperature interaction effects on development of Laminaria saccharina (Phaeophyta) gametophytes and juvenile sporophytes. J Phycol 24:181 191

Lobban CS, Harrison PJ (1994) Seaweed ecology and physiology. Cambridge University Press, New York, 366 pp

Macaya EC, Zucarello G (2010) DNA barcoding and genetic diver gence in the giant kelp Macrocystis (Laminariales). J Phycol 46: 736742

Murúa P, Westermeier R, Patiño DJ, Müller DG (2013) Culture studies on early development of Lessonia trabeculata (Phaeophyceae, Laminariales): seasonality and acclimation to light and temperature. Phycol Res 61:145 153

North WJ (1994) Review of Macrocystis biology. In: Akatsuka I (ed) Biology of Economic Algae. Academic Publishing, Hague, pp 447 527

Reed DC, Foster MS (1984) The effects of canopy shading on algal recruitment and growth of a giant kelp (Macrocystis pyrifera) forest. Ecology 65:937 948

Reed D, Ebeling AW, Anderson TW, Anghera M (1996) Differential reproductive responses to fluctuating resources in two seaweeds with different reproductive strategies. Ecology 77:300 316

Santelices B, Ojeda FP (1984a) Effects of canopy removal on the under story algal community structure of coastal forests of Macrocystis pyrifera from southern South America. Mar Ecol Prog Ser 14:165 173

Santelices B, Ojeda FP (1984b) Population dynamics of coastal forests of Macrocystis pyrifera in Puerto Toro, Isla Navarino, Southern Chile. Mar Ecol Prog Ser 14:175 183

Vásquez JA, Vega JMA, Buschmann AH (2006) Long term studies on El Niño La Niña in Northern Chile: effects on the structure and organization of subtidal kelp assemblages. J Appl Phycol 18: 505519

Vega JMA, Vásquez JA, Buschmann AH (2005) Population biology of the subtidal kelps Macrocystis integrifolia and Lessonia trabeculata (Laminariales, Phaeophyceae) in an upwelling ecosystem of Northern Chile: interannual variability and El Niño 19971998. Rev Chil Hist Nat 78:33 50

Westermeier R, Möller P (1990) Population dynamics of Macrocystis pyrifera (L.) C. Agardh in the rocky intertidal of southern Chile. Bot Mar 33:363 367

Westermeier R, Patiño DJ, Müller DG (2007) Sexual compatibility and hybrid formation between the giant kelp species Macrocystis pyrifera and M. integrifolia (Laminariales, Phaeophyceae) in Chile. J Appl Phycol 19:215 221

Westermeier R, Patiño D, Murúa P, Muñoz L, Ruiz A, Atero C (2012) Manual de repoblamiento de Macrocystis integrifolia en la región de Atacama. Proyecto FIC FNDR 2010 Región de Atacama. Universidad Austral de Chile. $47 \mathrm{pp}$

Westermeier R, Murúa P, Patiño D, Muñoz L, Ruiz A, Atero C, Müller DG (2013a) Utilization of holdfast fragments for vegetative propa gation of Macrocystis integrifolia in Atacama, Northern Chile. J Appl Phycol 25:639 642 
Westermeier R, Murúa P, Patiño D, Muñoz L, Ruiz A, Müller DG (2013b) Growth patterns of Chilean kelps holdfast after fragmentation: a novel repopulation approach. Abstracts 21st International Seaweed Symposium, Bali, $300 \mathrm{p}$.

Westermeier R, Murúa P, Patiño D, Muñoz L, Ruiz A, Atero C, Müller DG (2013c) Repopulation techniques for Macrocystis integrifolia (Phaeophyceae: Laminariales) in Atacama Chile. J Appl Phycol. doi:10.1007/s108110130069 5
Zar JH (1999) Biostatistical analysis, 4th edn. Prentice Hall, New Jersey, $663 \mathrm{p}$

Zavala P, Diaz H, Araneda P (2010) Segundo monitoreo de la biomasa de Macrocystis integrifolia (huiro canutillo), Lessonia trabeculata (huiro palo) y Heterozostera chilensis (pasto marino), mediante técnicas de teledetección aeroespacial en Bahía Chasco Región de Atacama. Informe técnico Geosensing ltda. 36 p. Available at: http://www. plataformacaldera.cl/biblioteca/589/w3 article 64468.html 